\title{
INOVAÇÃO NO ENSINO SUPERIOR
}

Lívia Raposo Bardy ${ }^{1}$, Elisa Tomoe Moriya Schlünzen², Danielle Aparecida do Nascimento dos Santos ${ }^{3}$

Universidade Estadual Paulista - UNESP, Programa de Pós-Graduação em Educação - PPGE, Presidente Prudente, SP. Universidade do Oeste Paulista - UNOESTE, Curso de Pedagogia a Distância, Presidente Prudente, SP. Fundação Dracenense de Educação e Cultura - UNIFADRA, Licenciaturas, Dracena, SP. ${ }^{2}$ Universidade Estadual Paulista - UNESP, Departamento de Estatística, Presidente Prudente, SP. ${ }^{3}$ Universidade do Oeste Paulista - UNOESTE, Programa de Pósgraduação em Educação e Coordenação do curso de Pedagogia a Distância, Presidente Prudente, São Paulo. ${ }^{3}$ Universidade Estadual Paulista - UNESP, Departamento de Estatística, Presidente Prudente, SP.

\section{RESUMO}

Nos últimos anos a preocupação com a qualidade do ensino e da formação realizada na Educação Superior tem aumentado significativamente no Brasil. Tal preocupação se estende para o desenvolvimento de práticas inovadoras com o uso das Tecnologias Digitais de Informação e Comunicação. Assim, a presente pesquisa de doutorado tem o objetivo de analisar os aspectos inerentes ao desenvolvimento de um curso de aperfeiçoamento ofertado no ano de 2015 aos docentes da Unesp, no âmbito do Programa Graduação Inovadora da Unesp em parceria com o Núcleo de Educação a Distância. Os docentes participantes do processo de formação foram estimulados a construir materiais didático-pedagógicos usando uma ferramenta digital intitulada "Publicador". A metodologia adotada é qualitativa. A coleta de dados inicial, que consiste na análise da concepção do curso, demonstra que a proposta tem articulação com os pressupostos do Programa, e atende aos parâmetros de inovação no Ensino Superior considerando a legislação vigente.

Palavras-chave: Ensino Superior, Inovação, Tecnologias Digitais de Informação e Comunicação.

\section{INNOVATION IN HIGHER EDUCATION}

\begin{abstract}
In recent years, concern about the quality of education and training carried out in higher education has increased significantly in Brazil. This concern extends to the development of innovative practices with the use of Digital Technologies of Information and Communication. So the doctoral research this aims to analyze aspects related to the development of an improvement course offered in 2015 to the Unesp teachers under the Undergraduate Innovative Unesp program in partnership with the Education Center Distance. The teachers participating in the training process were encouraged to build teaching-learning materials using a digital tool called "Publisher". The methodology is qualitative. The initial data collection, which is the analysis of the design of the course, shows that the proposal has conjunction with the conditions of the Program and meets the innovation criteria in higher education considering the legislation.
\end{abstract}

Keywords: Higher education, Innovation, Digital Technologies of Information and Communication. 


\section{INTRODUÇÃO}

A preocupação com a melhora da qualidade da educação é uma realidade crescente não somente do Brasil, mas em todos os países do mundo. Por isso, os estudos acadêmicos sobre a melhoria na qualidade dos processos de ensino e aprendizagem, bem como o uso das Tecnologias Digitais de Informação e Comunicação (TDIC) em tais processos tem sido amplamente desenvolvidos no contexto brasileiro. Muitos desses estudos têm se voltado para o Ensino Superior, tais como os de Almeida e Fonseca (2000), Masetto (2011) e Demo (2011).

Nesse sentido, autores como, Valente (2003), Moran et al (2002), Santos (2007) e Schlünzen $(2000,2015)$, afirmam que a inserção das TIDIC na educação deve ser feita por meio de metodologias capazes de que sejam usadas com qualidade dando sentido ao processo de ensino e aprendizagem. Além disso, a busca por desenvolver competências no estudante, sobretudo do Ensino Superior, como a autonomia, a criatividade e a criticidade, é uma meta a ser alcançada nas instituições de ensino em cenário mundial.

Em âmbito nacional, o Plano Nacional de Educação (PNE), que tem a vigência de 2014 a 2024, traz metas para o Ensino Superior, especificamente a meta 12 que tem o objetivo de elevar a qualidade nessa etapa de ensino e ainda o aumento das matrículas. Nessas metas, explicita-se a preocupação com a qualidade do ensino superior e com a presença inovadora do uso das tecnologias no processo de ensino e aprendizagem se faz presente na esfera nacional e em um plano de ação governamental.

Diante dessa vertente, a Universidade Estadual Paulista “Júlio de Mesquita Filho" (Unesp), tem proposto iniciativas para a formação de seu corpo docente visando, entre outros aspectos, o uso das TDIC nas práticas de ensino realizadas nos cursos de graduação da instituição.

O "Programa Graduação Inovadora na Unesp" foi estruturado no ano de 2014, e é resultante de uma das metas previstas no Plano de Desenvolvimento Institucional (PDI) da Universidade, com a intenção de formar os docentes que, embora tenham o desejo de inovar o ensino na graduação, não se sentem preparados o suficiente ou sentem que precisam de suporte e recursos para realizar ações que sejam consideradas inovadoras, especialmente no que se refere ao uso das TDIC.

Nesse interim, surge o parceria com o Núcleo de Educação a Distância (NEaD) da Unesp, que tem desenvolvido cursos no Portal Edutec, por meio do Ambiente Virtual de Aprendizagem (AVA) Moodle da Unesp.

Assim, a partir do ano de 2015, o NEaD realizou a Central de Cursos, uma ação voltada a criação e ao desenvolvimento de cursos, ligada ao "Programa Graduação Inovadora na Unesp", para que os docentes, discentes da pós-graduação e funcionários da Unesp pudessem realizar cursos a distância, sobre os temas: Formação de tutores, Práticas Pedagógicas para EaD, Aperfeiçoamento do Moodle, Licitação e Contratação Pública, Direitos Autorais na EaD, Princípios e Técnicas da Audiodecrição, Práticas Educacionais Inclusivas na Área da Deficiência Intelectual e Sustentabilidade.

O "Programa Graduação Inovadora na Unesp" tem como objetivo principal melhorar o ensino de graduação na Unesp, visando "a disseminação de uma cultura institucional, por meio de discussão, avaliação, implementação e valorização permanente das ações pedagógicas, em constante transformação, compatíveis com os avanços da ciência e da tecnologia".

Conforme consta na proposta do "Programa Graduação Inovadora na Unesp", seu objetivo principal é:

criar uma proposta político-didático pedagógica de melhoria do ensino de graduação na UNESP, a qual visa a disseminação de uma cultura institucional, por meio de discussão, avaliação, implementação e valorização permanente das ações pedagógicas, em constante transformação, compatíveis com os avanços da ciência e da tecnologia. 
Ou seja, tal Programa promove a formação para manejo de recursos digitais e a adaptação da infraestrutura dos cursos de graduação, incorporando metodologias ativas na prática pedagógica.

Dentre as inovações almejadas, espera-se que os docentes da Unesp compreendam como impregnar o uso das TDIC, desenvolver metodologias ativas de ensino, além de trabalhar em uma perspectiva inclusiva e colaborativa, visando que o Ensino Superior ofertado na instituição seja o mais qualitativo possível oportunizando aos estudantes aprendizagens significativas durante 0 processo de formação inicial compatíveis com os avanços da ciência e da tecnologia.

Na presente pesquisa de doutorado intitulada "Ações Inovadoras no Ensino Superior: uma experiência do "Programa Graduação Inovadora na Unesp" em parceria com o NEaD - Unesp ", o objeto consiste na análise do curso "Construção de Materiais Didático-Pedagógicos para ELearning, M-Learning e B-Learning", que faz parte do Programa Graduação Inovadora da Unesp.

O curso foi realizado no período de quatro meses de duração, carga horária de 100 horas divididas, em 10 semanas. Foram matriculados 393 cursistas, sendo docentes, estudantes da pósgraduação e funcionários da Unesp.

O objetivo do curso, de caráter de aperfeiçoamento, ou seja, operacional, foi o de auxiliar os cursistas a construir materiais didático-pedagógicos usando uma ferramenta denominada "Publicador de e-book", baseada em uma linguagem de programação aberta, dentro dos pressupostos da abordagem Construcionista, Contextualizada e Significativa (CCS) que, de acordo com Schlünzen (2015), permite que o sujeito da aprendizagem desenvolva um projeto ou resolva um problema, usando tecnologia, dentro de um contexto específico, por meio de uma construção para aprendizagem com significado.

A definição de CCS, conforme Schlünzen (2000), se dá da seguinte maneira: Construcionista porque o estudante usa a tecnologia como instrumento ou recurso para produzir um produto do seu interesse; Contextualizado porque o tema escolhido ou desenvolvido parte do contexto do estudante e, portanto se desenvolve mediante sua realidade; e é Significativo porque os estudantes, ao construir tal produto se deparam com os conceitos das disciplinas curriculares e o docente atua como mediador na formalização e sistematização desses conteúdos, para que o estudante atribua um significado aos mesmos (SANTOS, 2015).

Este artigo versa sobre os procedimentos para a coleta de dados no âmbito do curso, elaborado e desenvolvido em 2015.

\section{METODOLOGIA}

O projeto de pesquisa foi submetido ao Comitê de Ética, no entanto, até o presente momento ainda não saiu o resultado, considerando que está em fase de análise.

A pesquisa é de cunho qualitativo por oportunizar ao pesquisador a possibilidade de uma investigação mais íntima e detalhada com o campo de estudo, proporcionando maior reflexão a respeito dos dados coletados.

Inicialmente a coleta de dados foi realizada no AVA do curso, como ambiente fonte de dados a fim de obter informações sobre o desenvolvimento do curso, sobre o processo de formação ofertado aos participantes. Após a aprovação pelo comitê de ética está previsto o uso de instrumentos como questionários e entrevistas, que serão realizadas com os docentes participantes do curso. Com os questionários pretende-se selecionar os docentes que participarão da entrevista, de forma a contemplar cada uma das áreas do conhecimento, ou seja, com docentes que participaram do curso e que pertencem as áreas de humanas, exatas e biológicas. Para isso, será feito contato por meio de seus endereços eletrônicos e, quando possível, o contato será feito por meio de contato telefônico e até mesmo presencial, se as condições geográficas forem favoráveis. 
Espera-se que a análise de dados seja respaldada pelas etapas de coleta e seleção, tendo como base a fundamentação teórica levantada, em especial sobre inovações no Ensino Superior e sobre a abordagem CCS. Assim, espera-se buscar na literatura embasamento teórico sobre o uso de metodologias ativas que deverá permear todas as etapas da pesquisa. Além disso, serão feitas análises no AVA do curso em que os docentes foram participantes com o intuito de conhecer o material digital didático pedagógico por eles elaborados durante o desenvolvimento do curso e verificar se estão sendo utilizados em suas práticas docentes atuais.

\section{RESULTADOS}

Diante dos pressupostos e objetivos da pesquisa, e considerando que o "Programa Graduação Inovadora na Unesp", no âmbito do referido curso, trouxe suporte e apoio para que os docentes da Unesp pudessem começar a desenvolver estratégias de ensino usando ao ferramenta "Publicador de e-book". Por meio de uma análise preliminar observou-se de como se deu a articulação das ações vivenciadas no curso com a disciplina que o docente ministra na Unesp. Ou seja, procurou-se observar como material didático-pedagógico construído no percurso do curso realmente contribuiu para que esses docentes passassem a desenvolver ações consideradas inovadoras, mediante o uso de TDIC, conforme os pressupostos do Programa de forma acessível aos seus discentes. Para tanto, almeja-se fazer a triangulação dos dados coletados no AVA, nos instrumentos que utilizados (questionários ou entrevistas) com o que preconiza a legislação vigente sobre inovação no Ensino Superior e os autores que estudam a temática em âmbito nacional e internacional.

\section{DISCUSSÃO}

Mediante análise inicial da estrutura do curso e materiais disponibilizados, busca-se no momento compreender como se deu a articulação das ações vivenciadas no curso com as disciplinas que os docentes ministram na Unesp. Faz-se, para tanto, uma leitura sistemática do material didático-pedagógico construído no percurso do curso.

Até o momento as considerações feitas são no sentido de que o desenvolvimento do curso fomentou e buscou atender a uma demanda crescente e urgente no campo da produção de materiais didáticos digitais e a utilização de TDIC no Ensino Superior. Para isso, o foco tem sido a análise do sistema de elaboração de $e$-book, que ofereceu condições para que os docentes fossem capazes de elaborar o seu próprio material didático digital, integrando imagem, texto, animação, vídeo e jogos de forma acessível para os seus estudantes por meio de cursos ou disciplinas ofertadas no formato presencial ou semipresencial. Além disso, será analisada como foi a preparação dos materiais do curso "Construção de Materiais Didático-Pedagógicos para ELearning, M-Learning e B-Learning", bem como se deu seu desenvolvimento. Por isso, torna-se relevante dizer que no desenvolvimento do curso fez parte do conteúdo programático os seguintes conceitos: e-learning, m-learning, b-learning e materiais didáticos digitais; organização de conteúdos para a produção de e-books interativos e implementação de conteúdos no e-book.

\section{CONCLUSÃO}

Em um curso de formação desta natureza é importante fornecer ferramentas adequadas para o uso de TDIC, como no caso da ferramenta "Publicador de e-book". Neste sentido, em mudar sua prática pedagógica e tem com isso, buscando trazer inovação para o Ensino Superior.

Diante do que foi realizado até o momento, é importante salientar que espera-se que em um processo de formação permita a "Construção de Materiais Didático-Pedagógicos para ELearning, M-Learning e B-Learning", de forma que os docentes participantes percebam o sentido em mudar sua prática docente, procurando constantemente sentir se houve mudanças e se como consequências dessas mudanças houve inovação no Ensino Superior, fazendo-os tornar-se 
pesquisadores da sua própria prática. Além disso, espera-se conhecer como foi participar de um curso na abordagem CCS e se tal abordagem está presente de alguma forma na prática docente dos participantes.

\section{REFERÊNCIAS}

ALMEIDA, Maria Elizabeth; VALENTE, José Armando. Integração currículo e tecnologias e a produção de narrativas digitais. Currículo sem Fronteiras, v. 12, p. 57-82, 2012.

ALMEIDA, Maria Elisabeth. Gestão de tecnologias, mídias e recursos na escola: o compartilhar de significados. Brasília: $\quad 2009 . \quad$ INEP, Disponível em: http://emaberto.inep.gov.br/index.php/emaberto/article/viewFile/1435/1170, acesso em 04/09/2014.

ALMEIDA, Fernando; FONSECA JUNIOR, Fernando M. Projetos e Ambientes Inovadores. Brasília: Ministério da Educação/MEC, 2000.

BRASIL. Ministério da Educação. Lei de Diretrizes e Bases da Educação Nacional. LDB 9.394, de 20 de dezembro de 1996.

BRASIL. MINISTÉRIO DA EDUCAÇÃO. Portaria n.ㅇ 4.059, de 10 de dezembro de 2004. Disponível em: Acesso em: 12 jun./2008.

BRASIL, Ministério da Educação. Diretrizes Operacionais para a oferta de Educação a Distância (EAD), em regime de colaboração entre os sistemas de ensino. MEC/SEED. Brasília, 2012.

BRASIL. Plano Nacional de Educação (PNE). Plano Nacional de Educação 2014-2024 [recurso eletrônico]: Lei no 13.005, de 25 de junho de 2014, que aprova o Plano Nacional de Educação (PNE) e dá outras providências. - Brasília: Câmara dos Deputados, Edições Câmara, 2014. 86 p. (Série legislação; $\quad$ n. 125). Disponível em: http://www.observatoriodopne.org.br/uploads/reference/file/439/documento-referencia.pdf Acesso em: 10. Set.2015.

DEMO, P. Formação Permanente e Tecnologias Educacionais. Petrópolis, RJ: Vozes, 2011, 2a ed.

MASETTO, Marcos Tarcísio. Inovação Curricular no Ensino Superior. In: Revista e-Curriculum, São Paulo, v.7, no 2, Agosto 2011.

SANTOS, Danielle Aparecida do Nascimento dos. A formação de professores de uma escola da rede pública estadual em serviço para o trabalho com projetos usando as Tecnologias de Informação em Comunicação. Presidente Prudente, 2007. Dissertação (Mestrado em Educação) FCT/Unesp, 2007.

SANTOS, Danielle Aparecida do Nascimento dos. A abordagem CCS na formação de professores para uma escola inclusiva. Presidente Prudente, 2015. Tese (Doutorado em Educação) FCT/Unesp, 2015.

SCHLÜNZEN, Elisa Tomoe Moriya. Mudanças nas práticas pedagógicas do professor: criando um ambiente construcionista contextualizado e significativo para crianças com necessidades especiais físicas. São Paulo, 2000. Tese (Doutorado em Educação: Currículo) - PUC-SP, 2000. 
SCHLÜNZEN, K. J. Educação a distância no Brasil: caminhos, políticas e perspectivas. Revista Educação Temática Digital (ETD), v. 10, n. 2, Campinas, 2009.

VALENTE, José Armando. O papel da mediação e da interação na educação a distância: estabelecendo estratégias diferenciadas de ensino. In: TRINDADE, Maria Angela Bianconcini (org). As tecnologias de informação e comunicação (TIC) no Desenvolvimento de Profissionais do Sistema Único de Saúde (SUS). São Paulo: Instituto de Saúde, 2011. 